This item was submitted to Loughborough's Research Repository by the author.

Items in Figshare are protected by copyright, with all rights reserved, unless otherwise indicated.

\title{
A lead-free high-Curie-point ferroelectric ceramic, CaBi2Nb2O9
}

\section{PLEASE CITE THE PUBLISHED VERSION}

http://dx.doi.org/10.1002/adma.200401860

\section{PUBLISHER}

(C) 2005 WILEY-VCH Verlag GmbH \& Co. KGaA, Weinheim

\section{VERSION}

NA (Not Applicable or Unknown)

\section{PUBLISHER STATEMENT}

This work is made available according to the conditions of the Creative Commons Attribution-NonCommercialNoDerivatives 4.0 International (CC BY-NC-ND 4.0) licence. Full details of this licence are available at: https://creativecommons.org/licenses/by-nc-nd/4.0/

\section{LICENCE}

CC BY-NC-ND 4.0

\section{REPOSITORY RECORD}

Yan, Haixue, Hongtao Zhang, Rick Ubic, Michael J. Reece, Jing Liu, Zhijian Shen, and Zhen Zhang. 2015. "A Lead-free High-curie-point Ferroelectric Ceramic, Cabi2nb2o9". figshare. https://hdl.handle.net/2134/17763. 
96.3, 93.0, 91.3, 90.5, 87.2, 40.2, 29.7, -0.09. Fast-ion bombardment MS: $m / z 417[M]^{+}, 402\left[M-\mathrm{Me}^{+}, 386\left[M-2 \mathrm{Me}^{+}, 372\left[M-\mathrm{NMe}_{2}\right]^{+}\right.\right.$, $345\left[M-\mathrm{SiMe}_{3}\right]^{+}, 300\left[M-\mathrm{NMe}_{2}-\mathrm{SiMe}_{3}\right]^{+} . T_{\mathrm{d}}=245^{\circ} \mathrm{C}$.

Dimethyl-[4-(4-\{4-[(triisopropylsilanyl)ethynyl]phenylethynyl\}phenylethynyl)phenyl]amine (3): Yield: $89 \%$. Anal. Calcd. for $\mathrm{C}_{35} \mathrm{H}_{39} \mathrm{NSi}$ : C, 83.78; H, 7.83; N, 2.79. Found: C, 83.24; H, 7.61; N, 2.34. ${ }^{1} \mathrm{H} N M R$ $\left(400 \mathrm{MHz}, \mathrm{CDCl}_{3}\right): \delta 7.48-7.38(\mathrm{~m}, 10 \mathrm{H}), 6.68-6.63(\mathrm{~m}, 2 \mathrm{H}), 3.00$ (s, 6H), $1.13(\mathrm{~s}, 21 \mathrm{H}) .{ }^{13} \mathrm{CNMR}\left(100 \mathrm{MHz}, \mathrm{CDCl}_{3}\right): \delta 150.3,132.8$, 132.0, 131.5, 131.3, 131.2, 124.3, 123.4, 123.0, 121.8, 111.8, 109.7, 106.7, 93.0, 92.9, 91.2, 90.6, 87.3, 40.2, 18.7, 11.3, 0.0. FAB MS: $\mathrm{m} / z$ $501[\mathrm{M}]^{+}$. $T_{\mathrm{d}}=315^{\circ} \mathrm{C}$

For the bottom-contact devices, layers of the oligo(arylacetylene)s with thicknesses of ca. $50 \mathrm{~nm}$ were deposited on the Au-patterned $\mathrm{SiO}_{2} / \mathrm{Si}$ substrates at room temperature under high-vacuum condition $\left(3 \times 10^{-4} \mathrm{~Pa}\right)$. For the top-contact devices, the active organic layer $(50 \mathrm{~nm})$ was deposited on $100 \mathrm{~nm} \mathrm{SiO} 2$ substrates followed by the deposition of a gold electrode on the top using different masks for organic and metal layers. The devices fabricated on untreated substrates were tested in a microprobe station to measure the current-voltage characteristics of the devices under ambient conditions.

Received: December 7, 2004

Final version: February 12, 2005

[1] G. Horowitz, Adv. Mater. 1998, 10, 365 .

[2] F. Garnier, Chem. Phys. 1998, 227, 253.

[3] H. E. Katz, J. Mater. Chem. 1997, 7, 369.

[4] F. Garnier, R. Hajlaoui, A. Yassar, P. Srivastava, Science 1994, 265, 1684.

[5] C. D. Dimitrakopoulos, P. R. L. Malenfant, Adv. Mater. 2002, 14, 99.

[6] B. Comiskey, J. D. Albert, H. Yoshizawa, J. Jacobson, Nature 1998, 394, 253.

[7] M. L. Chabinyc, A. Salleo, Chem. Mater. 2004, 16, 4509.

[8] M. Halik, H. Klauk, U. Zschieschang, G. Schmid, C. Dehm, M. Schütz, S. Maisch, F. Effenberger, M. Brunnbauer, F. Stellacci, Nature 2004, 431, 963 .

[9] O. D. Jurchescu, J. Baas, T. T. M. Palstra, Appl. Phys. Lett. 2004, 84, 3061.

[10] F. Garnier, R. Hajlaoui, A. El Kassmi, G. Horowitz, L. Laigre, W. Porzio, M. Armanini, F. Provasoli, Chem. Mater. 1998, 10, 3334.

[11] a) H. Sirringhaus, N. Tessler, R. H. Friend, Science 1998, 280, 1741. b) H. Sirringhaus, P. J. Brown, R. H. Friend, M. M. Nielsen, K. Bechgaard, B. M. W. Langeveld-Voss, A. J. H. Spiering, R. A. J. Janssen, E. W. Meijer, P. Herwig, D. M. de Leeuw, Nature 1999, 401, 685. c) R. D. McCullough, Adv. Mater. 1998, 10, 93.

[12] J. G. Laquindanum, H. E. Katz, A. J. Lovinger, J. Am. Chem. Soc. 1998, 120, 664.

[13] R. E. Martin, F. Diederich, Angew. Chem. Int. Ed. 1999, 38, 1350.

[14] a) A. Beeby, K. Findlay, P. J. Low, T. B. Marder, J. Am. Chem. Soc. 2002, 124, 8280. b) J. Kim, I. A. Levitsky, D. T. McQuade, T. M. Swager, J. Am. Chem. Soc. 2002, 124, 7710. c) J. Cornil, Y. Karzazi, J. L. Brédas, J. Am. Chem. Soc. 2002, 124, 3516. d) M. I. Sluch, A. Godt, U. H. F. Bunz, M. A. Berg, J. Am. Chem. Soc. 2001, 123, 6447. e) M. Levitus, K. Schmieder, H. Ricks, K. D. Shimizu, U. H. F. Bunz, M. A. Garcia-Garibay, J. Am. Chem. Soc. 2001, 123, 4259.

[15] a) A. M. McDonagh, M. G. Humphrey, M. Samoc, B. Luther-Davies, S. Houbrechts, T. Wada, H. Sasabe, A. Persoons, J. Am. Chem. Soc. 1999, 121, 1405. b) K. D. John, M. D. Hopkins, Chem. Commun. 1999, 589. c) Y. G. Ma, W. H. Chan, X. M. Zhou, C. M. Che, New J. Chem. 1999, 23, 263. d) S. C. Chan, M. C. W. Chan, Y. Wang, C. M. Che, K. K. Cheung, N. Y. Zhu, Chem. Eur. J. 2001, 7, 4180. e) W. Lu, B. X. Mi, M. C. W. Chan, Z. Hui, N. Y. Zhu, S. T. Lee, C. M. Che, Chem. Commun. 2002, 206. f) H. Y. Chao, W. Lu, Y. Li, M. C. W. Chan, C. M. Che, K. K. Cheung, N. Y. Zhu, J. Am. Chem. Soc. 2002, 124, 14696

[16] S. Anderson, Chem. Eur. J. 2001, 7, 4706.
[17] a) U. H. F. Bunz, Chem. Rev. 2000, 100, 1605. b) A. Kraft, A. C. Grimsdale, A. B. Holmes, Angew. Chem. Int. Ed. 1998, 37, 402. c) C. Weder, C. Sarwa, A. Montali, C. Bastiaansen, P. Smith, Science 1998, 279, 835. d) A. Montali, C. Bastiaansen, P. Smith, C. Weder, Nature 1998, 392, 261

[18] J. M. Tour, Acc. Chem. Res. 2000, 33, 791.

[19] D. T. McQuade, A. E. Pullen, T. M. Swager, Chem. Rev. 2000, 100, 2537.

[20] K. T. Wong, F. C. Fang, Y. M. Cheng, P. T. Chou, G. H. Lee, Y. Wang, J. Org. Chem. 2004, 69, 8038 .

[21] Z. J. Donhauser, B. A. Mantooth, K. F. Kelly, L. A. Bumm, J. D. Monnell, J. J. Stapleton, D. W. Price, Jr., A. M. Rawlett, D. L. Allara, J. M. Tour, P. S. Weiss, Science 2001, 292, 2303.

[22] a) K. Sonogashira, Y. Tohda, N. Hagihara, Tetrahedron Lett. 1975, 16, 4467. b) O. Lavastre, L. Ollivier, P. H. Dixneuf, S. Sibandhit, Tetrahedron 1996, 52, 5495.

[23] M. J. Powell, Appl. Phys. Lett. 1983, 43, 597.

[24] M. Matters, D. M. de Leeuw, P. T. Herwig, A. R. Brown, Synth. Met. 1999, 102, 998 .

\section{A Lead-Free High-Curie-Point Ferroelectric Ceramic, $\mathrm{CaBi}_{2} \mathrm{Nb}_{2} \mathrm{O}_{9}{ }^{* *}$}

\author{
By Haixue Yan, Hongtao Zhang, Rick Ubic, \\ Michael J. Reece, ${ }^{*}$ Jing Liu, Zhijian Shen, and \\ Zhen Zhang
}

High-temperature sensing technology is of major importance for chemical and material processing, as well as the automotive, aerospace, and power-generating industries. Electromechanical transducing materials are required to sense strains, vibrations, and noise under severe thermal conditions. Among the different types of acoustic and strain sensors, piezoelectrics offer the best candidates when one considers sensitivity, cost, and design. ${ }^{[1]}$ When an operating temperature of $400{ }^{\circ} \mathrm{C}$ or greater is required, the choice of materials for high-temperature piezoelectric transducers is limited. Although some single crystals such as $\mathrm{LiNbO}_{3},{ }^{[1]} \mathrm{La}_{3} \mathrm{Ga}_{5} \mathrm{SiO}_{14},{ }^{[2,3]} \mathrm{Sr}_{2} \mathrm{Nb}_{2} \mathrm{O}_{7},{ }^{[4]}$ and $\mathrm{A}_{2} \mathrm{Ti}_{2} \mathrm{O}_{7}$ (where $\mathrm{A}$ is $\mathrm{La}$ or $\mathrm{Nd}$ ) ${ }^{[5]}$ are good commercial or potential candidates for high-temperature piezoelectric applications, the cost of single crystals is very much higher than that of polycrystalline piezoceramics. ${ }^{[1,2]}$ Another important ad-

[*] Dr. M. J. Reece, Dr. H. Yan, H. Zhang, Dr. R. Ubic Department of Materials, Queen Mary University of London Mile End Road, London, E1 4NS (UK) E-mail: m.j.reece@qmul.ac.uk

J. Liu, Dr. Z. Shen

Department of Inorganic Chemistry, Arrhenius Laboratory Stockholm University S-10691, Stockholm (Sweden)

Z. Zhang

Shanghai Institute of Ceramics, Chinese Academy of Sciences 1295 Dingxi Road, Shanghai, 200050 (P. R. China)

[**] This research was funded by QinetiQ Ltd under contract number CU004-16541 and the Swedish Research Council through grant 6212002-4299. 
vantage $^{[2]}$ of polycrystalline piezoceramics over single crystals is the ease with which composition and properties may be tailored. Modified bismuth titanate compositions are interesting for sensor applications up to $500{ }^{\circ} \mathrm{C}^{[2]}$ When an operating temperature of up to $750^{\circ} \mathrm{C}$ is required, there is no suitable commercial polycrystalline ceramic available. ${ }^{[1,2]}$ In this communication, we report on a textured lead-free high-Curiepoint $\left(T_{\mathrm{c}}\right)$ ferroelectric polycrystalline ceramic, $\mathrm{CaBi}_{2} \mathrm{Nb}_{2} \mathrm{O}_{9}$ (CBNO), which has the highest-known $T_{\mathrm{c}}\left(943^{\circ} \mathrm{C}\right)$ of the Aurivillius-phase-structured materials, and the highest thermal-depoling temperature $\left(800^{\circ} \mathrm{C}\right)$ for a polycrystalline ferroelectric ceramic. The $T_{\mathrm{c}}$ corresponds to the paraelectric-ferroelectric transition and is associated with an anomaly in the dielectric constant. It therefore sets the upper temperature limit on the application of ferroelectric ceramics for piezoelectric applications. The CBNO ceramic is a good lead-free candidate for high-temperature piezoelectric applications up to $800^{\circ} \mathrm{C}$.

Both bismuth titanate $\left(\mathrm{Bi}_{4} \mathrm{Ti}_{3} \mathrm{O}_{12}\right)$ and $\mathrm{CBNO}$ are bismuth layer-structured ferroelectrics (BLSFs) in the Aurivillius phase family of materials. Aurivillius materials have attracted considerable attention for their potential use in non-volatile ferroelectric random-access memory $(\mathrm{FRAM})^{[6,7]}$ and high-temperature piezoelectric applications ${ }^{[8,9]}$ because they are fatigue-free and have high values of $T_{\mathrm{c}}$, respectively. The general formula of Aurivillius phase materials is $\left(\mathrm{Bi}_{2} \mathrm{O}_{2}\right)^{2+}\left(\mathrm{A}_{m-1} \mathrm{~B}_{m} \mathrm{O}_{3 m+1}\right)^{2-}$, where $\mathrm{A}$ is a mono-, di-, or trivalent element (or combination) with cuboctahedral coordination, B is a transition element suited to octahedral coordination, and $m$ is the number of octahedral layers in the perovskite slab. The $m$ value can vary from 1 to $6{ }^{[10]}$ The spontaneous polarization $P_{\mathrm{s}}$ for $\mathrm{CaBi}_{2} \mathrm{Nb}_{2} \mathrm{O}_{9}$ is along the $a$-axis direction. As a consequence of the anisotropy of microstructures and the properties of Aurivillius phase materials, texturing technologies, such as hot-forging ${ }^{[11]}$ and templated grain growth, ${ }^{[9]}$ can improve their electrical properties. Spark plasma sintering (SPS) is a new sintering process. It enhances the densification and superplastic deformation of ceramics through pulsed-electrical-current heating, producing highdensity, textured materials. ${ }^{[12,13]}$ To our knowledge, there are so far no reports on the microstructures or properties of textured $\mathrm{CBNO}$ ceramics. In the present work, piezoelectric ceramics $\mathrm{CaBi}_{2} \mathrm{Nb}_{2} \mathrm{O}_{9}$ were fabricated by ordinary firing $(\mathrm{OF})$ and SPS.

Figure 1 shows X-ray diffraction (XRD) patterns of SPS ceramic surfaces cut perpendicular and parallel to the hot-pressing direction compared with a pattern of non-textured $\mathrm{OF}$ CBNO ceramic. The diffraction peaks are matched and indexed based on $\mathrm{CBNO}^{[14]}$ crystal-structure parameters. The materials are all single-phase within the sensitivity of the technique. The XRD pattern parallel to the hot-pressing direction exhibited strong $(00 l)$ diffraction peaks, while the pattern perpendicular to the hot-pressing direction showed weak $(00 l)$ peaks and a strong $(020) /(200)$ peak. This indicates that the SPS samples were highly textured. The strongest diffraction peak for OF CBNO was (115), which is consistent with the

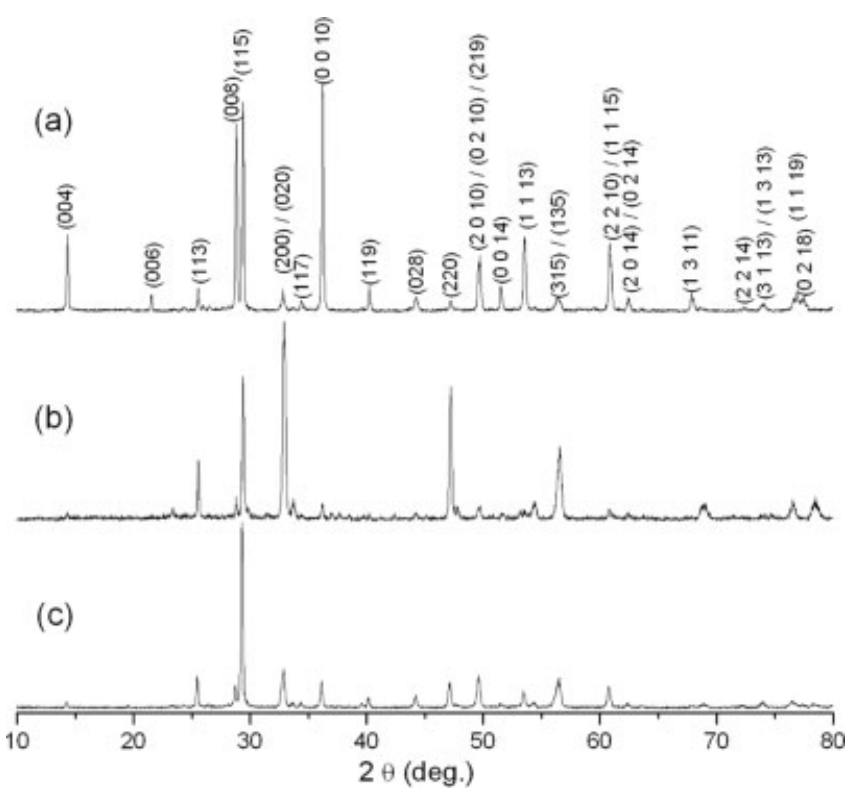

Figure 1. XRD patterns of CBNO surface obtained by cutting a) perpendicular and b) parallel to the hot-pressing direction in SPS samples, and c) OF sample.

$(112 m+1)$ highest diffraction peak in Aurivillius phases. ${ }^{[15]}$ Figure 2 shows the secondary electron scanning electron microscopy (SEM) images of the polished then thermally etched surfaces perpendicular and parallel to the hot-pressing direction of the SPS and OF CBNO ceramics. The grains are oriented for the SPS sample, which is consistent with the XRD results in Figure 1.

Pure CBNO has $A 2_{1}$ am orthorhombic symmetry ${ }^{[16]}$ with the polarization along the $a$-axis. Atomic displacements along the $a$-axis from the corresponding positions in the parent tetragonal $(I 4 / \mathrm{mmm})$ structure cause ferroelectric spontaneous polarization $P_{\mathrm{s}}$. Polarization caused by displacements along the $b$ and $c$-axes are cancelled due to the presence of glide and mirror planes, respectively, and thus do not contribute to the total $P_{\mathrm{s}}$. Based on the atomic displacements, the total $P_{\mathrm{s}}$ of the displacive-type ferroelectric CBNO was calculated using Shimakawa's model, ${ }^{[17]}$

$P_{\mathrm{s}}=\sum_{i} \frac{m_{i} \Delta x_{i} Q_{i} e}{V}$

where $m_{i}$ is the site multiplicity, $\Delta x_{i}$ is the atomic displacement along the $a$-axis from the corresponding position in the tetragonal structure, $Q_{i} e$ is the ionic charge of the $i$ th constitute ion, and $V$ is the volume of the unit cell. In terms of the crystal structure parameters of CBNO reported by Blake et al. ${ }^{[18]}$ the ion displacements along the $a$-axis and the contributions of each constituent ion to the total ferroelectric polarization are calculated in Figure 3. Based on Rietveld analysis of XRD and neutron-diffraction data, Blake et al. ${ }^{[18]}$ suggested that CBNO showed some chemical disorder on both the perovskite A-site and $\mathrm{Bi}_{2} \mathrm{O}_{2}$ layer. There is about 5.3 at.- $\%$ calcium on the bismuth site in the $\mathrm{Bi}_{2} \mathrm{O}_{2}$ layer. The calcium in 

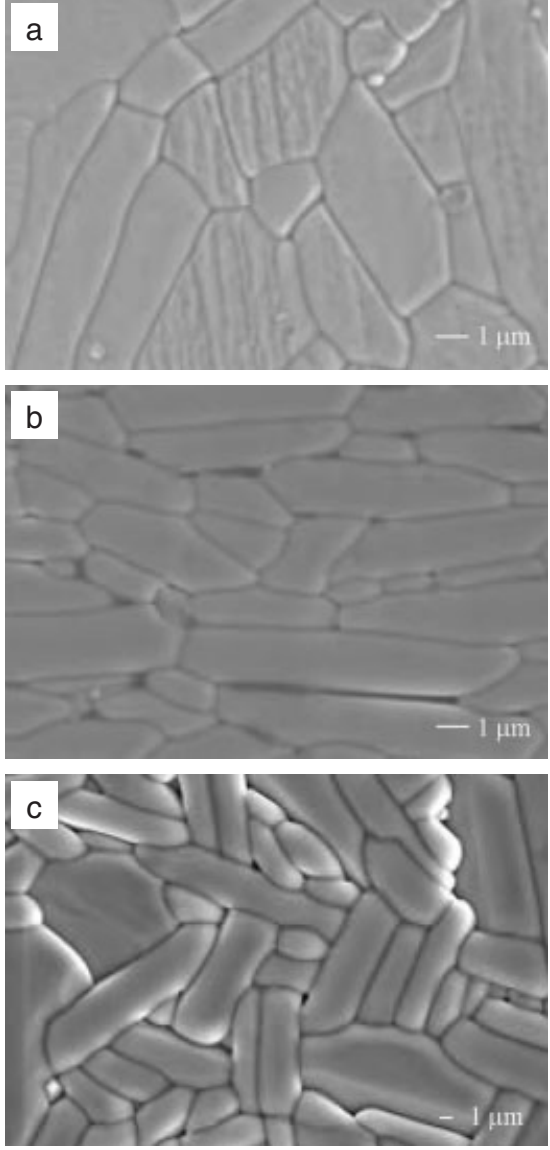

Figure 2. Secondary electron SEM images of polished then thermally etched surfaces for a) perpendicular, b) parallel to the hot-pressing direction in SPS samples, c) OF sample.

the $\mathrm{Bi}_{2} \mathrm{O}_{2}$ layer and bismuth in A-site are labeled as $\mathrm{Ca}(2)$ and $\mathrm{Bi}(1)$, respectively, in Figure 3.

Figure 4 shows the polarization-electric field $(P-E)$ hysteresis loops for CBNO samples. The remanent polarization $P_{\mathrm{r}}[\perp]$ is highest perpendicular to the hot-pressing direction in the textured SPS sample. The reason for this is that the ferroelectric polarization switching occurs in the $a-b$ plane in CBNO. Due to the lower limit on the sample thickness $(0.10$ $0.15 \mathrm{~mm}$ ) imposed by porosity and the maximum available voltage $(4 \mathrm{kV})$ and the conductivity at high voltages, it was not possible to obtain saturated $P-E$ hysteresis loops because of the evidently high coercive field $\left(E_{\mathrm{c}}\right)$ of CBNO. Similar problems have been previously noted for high- $T_{\mathrm{c}} \mathrm{Bi}_{3} \mathrm{NbTiO}_{9}$ ceramics. ${ }^{[8]}$ Consequently, the values of $P_{\mathrm{r}}[\perp]$ for CBNO are much less than the theoretical spontaneous polarization calculated in Figure 3.

In spite of their relatively large $P_{\mathrm{s}}$, the piezoelectric activity of ordinary fired BLSFs ceramics is limited because of the two-dimensional orientation restriction of the rotation of their spontaneous polarization $P_{\mathrm{s}}$ and their high coercive field $E_{\mathrm{c}}$. Textured processing is an effective method to improve piezoelectric activity of BLSFs because of the anisotropy of their
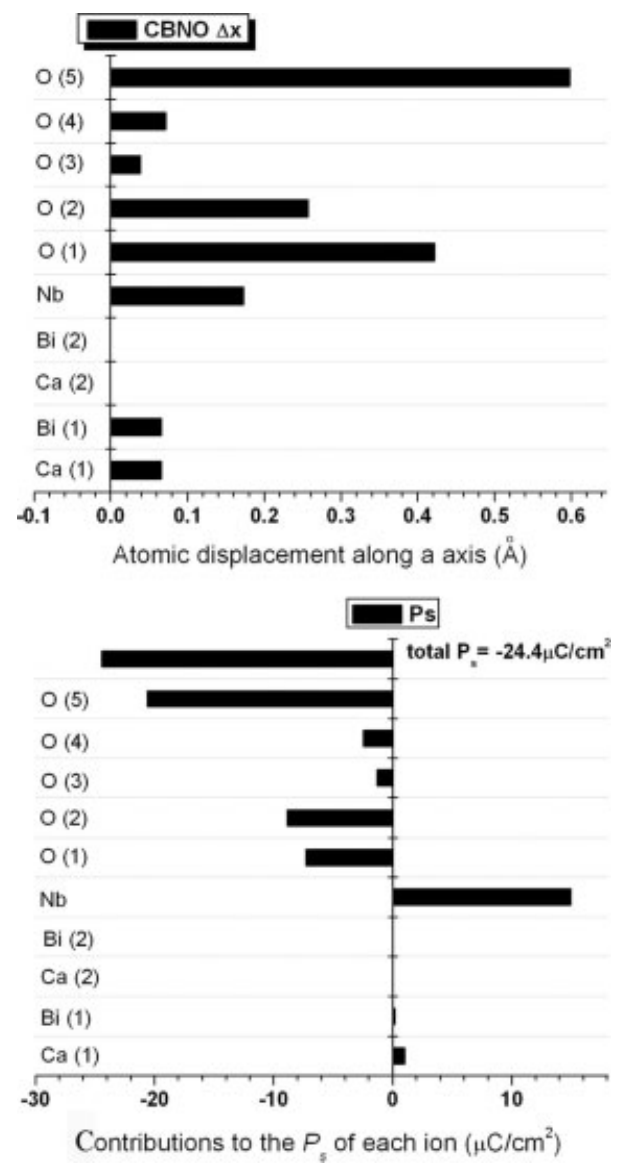

Figure 3. Ion displacement and contribution to the total spontaneous polarization $P_{\mathrm{s}}$ of each ion of $\mathrm{CaBi}_{2} \mathrm{Nb}_{2} \mathrm{O}_{9}$.

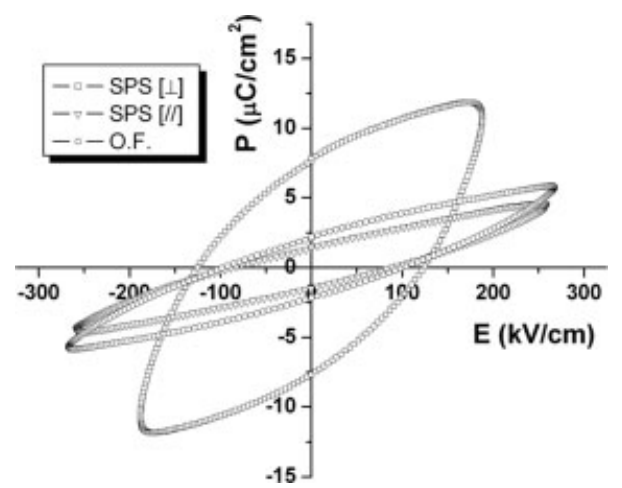

Figure 4. $P-E$ hysteresis loops of CBNO ceramics.

microstructures and properties. The average piezoelectric constant $d_{33}$ of three samples each of SPS [ $\left.\perp\right]$, SPS [\|], and OF CBNO samples were $19.5 \pm 0.3 \mathrm{pCN}^{-1}, 0.2 \pm 0.1 \mathrm{pCN}^{-1}$, and $7.5 \pm 0.2 \mathrm{pCN}^{-1}$, respectively.

Both $\mathrm{Bi}_{3} \mathrm{NbTiO}_{9}(\mathrm{BNTO})$ and $\mathrm{CaBi}_{2} \mathrm{Nb}_{2} \mathrm{O}_{9}(\mathrm{CBNO})$ are BLSFs with $m=2$ in which the A-site cations are $\mathrm{Bi}^{3+}$ and $\mathrm{Ca}^{2+}$, respectively. The Curie point $\left(914^{\circ} \mathrm{C}\right)$ of $\mathrm{BNTO}^{[19]}$ is 
higher than that reported by Ismailzade ${ }^{[20]}$ for CBNO (below $650^{\circ} \mathrm{C}$ ). This is inconsistent with Subbarao's suggestion ${ }^{[21]}$ that the Curie point of Aurivillius-phase materials increases with the decrease in the A-site cation size because the effective radius of $\mathrm{Ca}^{2+}$ is smaller than that of $\mathrm{Bi}^{3+} \cdot{ }^{[22]}$ Figure 5 shows the temperature dependence of dielectric constant $\left(\varepsilon_{r}\right)$ and loss $(D)$ of $\mathrm{CBNO}$ at $1 \mathrm{MHz}$. We also studied the temperature dependence of the dielectric constant at different frequencies

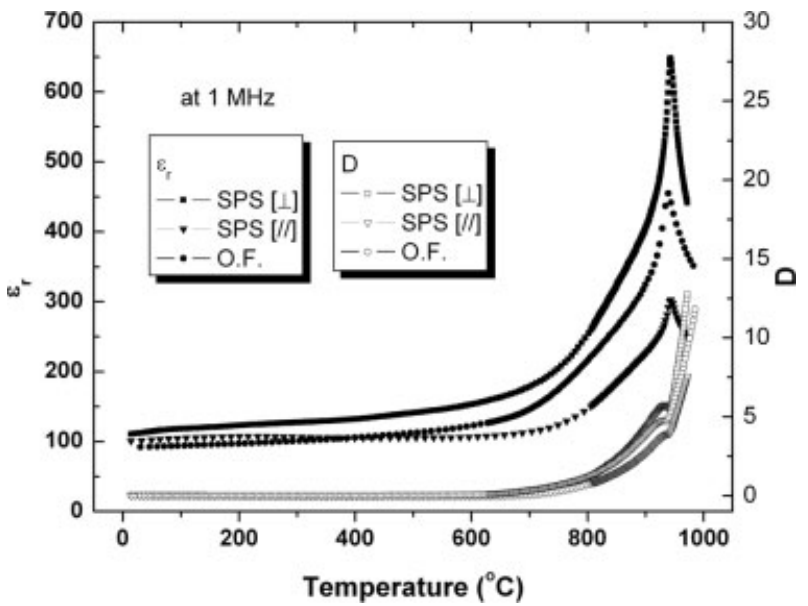

Figure 5. Temperature dependence of dielectric constant $\left(\varepsilon_{r}\right)$ and loss $(D)$ in CBNO ceramics.

and found no dispersion in the temperature of the dielectric anomaly. The Curie point of SPS CBNO samples perpendicular and parallel to the hot-pressing direction was $943 \pm 2{ }^{\circ} \mathrm{C}$, which is very close to that of OF CBNO ceramics $\left(940 \pm 2{ }^{\circ} \mathrm{C}\right)$. These values of the Curie point are much higher than the $650{ }^{\circ} \mathrm{C}$ reported by Ismailzade ${ }^{[20]}$ for CBNO. The fact that the Curie point $\left(940^{\circ} \mathrm{C}\right)$ of $\mathrm{CBNO}$ was found to be higher than that of BNTO $\left(914^{\circ} \mathrm{C}\right)^{[19]}$ is consistent with Subbarao's work. ${ }^{[21]}$ The effective radius of $\mathrm{Ca}^{2+}$ is smaller than that of $\mathrm{Bi}^{3+}$ for any coordination. ${ }^{[22]}$ Ismailzade's result ${ }^{[20]}$ for $T_{\mathrm{c}}$ may be in error because it was obtained with the assumption that it coincided with a phase transformation observed by XRD. The piezoelectric constant of BNTO is also lower than that of CBNO.

The dielectric constant and loss in the SPS samples is greater perpendicular to than parallel to the hot-pressing direction. The dielectric constant of OF CBNO is smaller than that of both SPS $[\perp]$ and SPS $[\|]$ CBNO at room temperature. Similar results were found by Seth and Schulze ${ }^{[23]}$ in textured $\mathrm{Bi}_{4}$ $\mathrm{Ti}_{3} \mathrm{O}_{12}$ ceramics. At higher temperatures $\left(\sim 400^{\circ} \mathrm{C}\right)$, the dielectric constant of OF samples is lower than that of SPS $[\perp]$ but higher than that of SPS [\|] samples. This behavior is the typical dependence of dielectric constant on temperature for BLSFs. ${ }^{[11,24]}$ The loss peaks just below the Curie points can be attributed to the movement of domain walls in BLSFs.

The thermal-depoling behavior of the OF and SPS $[\perp]$ CBNO samples is shown in Figure 6, in which piezoelectric

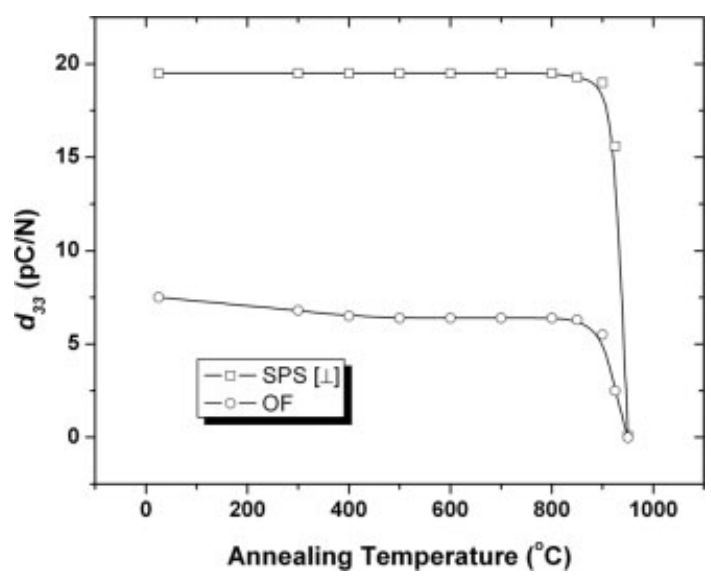

Figure 6. Effect of annealing temperature (for $2 \mathrm{~h}$ ) on the piezoelectric constant $d_{33}$ of CBNO ceramics.

constants $d_{33}$ are plotted against the annealing temperature. The $d_{33}$ value of OF CBNO decreased slightly with temperature up to $400^{\circ} \mathrm{C}$ and was then stable up to $800^{\circ} \mathrm{C}$. The $d_{33}$ of the SPS $[\perp]$ sample was stable up to $800^{\circ} \mathrm{C}$, and dropped rapidly above $900^{\circ} \mathrm{C}$.

In summary, the ferroelectric, dielectric, and piezoelectric properties of single-phase OF and SPS $\mathrm{CaBi}_{2} \mathrm{Nb}_{2} \mathrm{O}_{9}$ ceramics were characterized. The Curie point of textured $\mathrm{CaBi}_{2} \mathrm{Nb}_{2} \mathrm{O}_{9}$ $\left(943^{\circ} \mathrm{C}\right)$ was found to be much higher than its previously reported value (below $650{ }^{\circ} \mathrm{C}$ ). The calculated total $P_{\mathrm{s}}$ of $\mathrm{CaBi}_{2} \mathrm{Nb}_{2} \mathrm{O}_{9}$ is $24.4 \mu \mathrm{C} \mathrm{cm}^{-2}$. The $d_{33}$ of textured materials was nearly three times that of conventionally sintered materials. Thermal-depoling studies demonstrated that $d_{33}$ was stable up to $800{ }^{\circ} \mathrm{C}$ in textured $\mathrm{CaBi}_{2} \mathrm{Nb}_{2} \mathrm{O}_{9}$. Therefore, a combination of high $T_{\mathrm{c}}$, stable $d_{33}$, and high thermal-depoling temperature indicates that textured $\mathrm{CBNO}$ is a very promising material for high-temperature (up to $800^{\circ} \mathrm{C}$ ) piezoelectric applications.

\section{Experimental}

The starting materials were $\mathrm{Bi}_{2} \mathrm{O}_{3}$ of $99.975 \%$ purity, $\mathrm{CaCO}_{3}$ of $99 \%$ purity, and $\mathrm{Nb}_{2} \mathrm{O}_{5}$ of $99.9 \%$ purity. The $\mathrm{CBNO}$ powders were calcined at $950{ }^{\circ} \mathrm{C}$ for $4 \mathrm{~h}$. The textured CBNO ceramics were prepared by SPS using a Dr. Sinter 2050 facility (Sumitomo Coal Mining Co. Ltd., Japan). At first, the CBNO powder was consolidated in a graphite die at $925^{\circ} \mathrm{C}$ for 3 min under a pressure of $100 \mathrm{MPa}$ to produce a dense ceramic. The fully densified ceramic tablet with a diameter of $12 \mathrm{~mm}$ and thickness of $7.3 \mathrm{~mm}$ was then deformed in another graphite die with a larger inner diameter of $20 \mathrm{~mm}$ at $1150{ }^{\circ} \mathrm{C}$ for 5 min under a constant load that corresponded to an initial compressive stress of $40 \mathrm{MPa}$ to reach a total strain of $67 \%$. The heating rate for SPS was $100{ }^{\circ} \mathrm{C} \mathrm{min}^{-1}$. In order to remove the carbon from the textured samples, the ceramics were subsequently annealed at $1000^{\circ} \mathrm{C}$ for $4 \mathrm{~h}$ in air. The textured ceramics were cut perpendicular and parallel to the hot-pressing direction. The OF CBNO ceramics were sintered at $1065^{\circ} \mathrm{C}$ for $1 \mathrm{~h}$ in air.

XRD patterns for the ceramics were obtained with an X-ray diffractometer (Siemens D5000) using $\mathrm{Cu} \mathrm{K} \alpha$ radiation. The microstructures of the ceramic samples were observed by SEM (JEOL JSM 6300). The SEM samples were thermally etched at about $70^{\circ} \mathrm{C}$ below their sintering temperatures for $15 \mathrm{~min}$ to reveal their grain structure. 
Electrodes for room-temperature and high-temperature electricalproperty measurements were fabricated with fired-on silver paste (Johnson Matthey, E1100) and palladium paste (Gwent Electronic Materials Ltd., C2011004D5), respectively. Samples for piezoelectric measurements were poled in silicone oil at $200^{\circ} \mathrm{C}$ under various direct-current (DC) electric fields $\left(15-20 \mathrm{kV} \mathrm{mm}^{-1}\right)$. The piezoelectric constant $d_{33}$ was measured using a quasi-static $d_{33}$ meter (CAS, ZJ3B). The ferroelectric polarization-electric field $(P-E)$ hysteresis loops were measured by a ferroelectric hysteresis measurement tester (NPL, UK). The temperature dependence of dielectric constant and loss were measured at $1 \mathrm{MHz}$ using an Agilent 4284A LCR meter connected to a furnace. Thermal-depoling experiments were conducted by holding the poled samples with Pt electrodes for $2 \mathrm{~h}$ at various high temperatures, cooling to room temperature, measuring $d_{33}$, and repeating the procedure up to $950^{\circ} \mathrm{C}$.

Received: November 12, 2004 Final version: January 27, 2005

[1] R. C. Turner, P. A. Fuierer, R. E. Newnham, T. R. Shrout, Appl. Acoust. 1994, 41, 299

[2] D. Damjanovic, Curr. Opin. Solid-State Mater. Sci. 1998, 3, 469.

[3] J. Hornsteiner, E. Born, E. Riha, Phys. Status Solidi A 1997, 163, R3.

[4] S. Nanamatsu, M. Kimura, T. Kawamura, J. Phys. Soc. Jpn. 1975, 38, 817.

[5] J. K. Yamaoto, A. S. Bhalla, J. Appl. Phys. 1991, 70, 4469.

[6] C. Dearaujo, J. D. Cuchiaro, L. D. McMillan, M. C. Scott, J. F. Scott, Nature 1995, 374, 627

[7] B. H. Park, B. S. Kang, S. D. Bu, T. W. Noh, J. Lee, W. Jo, Nature 1999, 401, 682.

[8] L. Pardo, A. Castro, P. Millan, C. Alemany, R. Jimenez, B. Jimenez, Acta Mater. 2000, 48, 2421.

[9] S. H. Hong, S. Trolier-Mckinstry, G. L. Messing, J. Am. Ceram. Soc. 2000, 83,113 .

[10] Y. Wu, M. J. Forbess, S. Seraji, S. J. Limmer, T. P. Chou, C. Nguyen, G. Cao, J. Appl. Phys. 2001, 90, 5296.

[11] K. Shoji, M. Aikawa, Y. Uehara, K. Sakata, Jpn. J. Appl. Phys., Part 1 1998, 37, 5273

[12] Z. Shen, H. Peng, M. Nygren, Adv. Mater. 2003, 15, 1006.

[13] Z. Shen, E. Adolfsson, M. Nygren, Adv. Mater. 2001, 13, 214.

[14] Powder Diffraction File (PDF) No. 49-608.

[15] X. F. Du, I. W. Chen, J. Am. Ceram. Soc. 1998, 81, 3253.

[16] R. E. Newnham, R. W. Wolfe, J. F. Dorrian, Mater. Res. Bull. 1971, $6,1029$.

[17] Y. Shimakawa, Y. Kubo, Y. Nakagawa, S. Goto, T. Kamiyama, H. Asano, F. Izumi, Phys. Rev. B: Condens. Matter Mater. Phys. 2000, 61,6559 .

[18] S. M. Blake, M. J. Falconer, M. McCreedy, P. Lightfoot, J. Mater. Chem. 1997, 7, 1609.

[19] Z. Zhang, H. Yan, P. Xiang, X. Dong, Y. Wang, J. Am. Ceram. Soc. 2004, 87,602 .

[20] I. G. Ismailzade, Bull. Acad. Sci. USSR, Phys. Ser. (Engl. Transl.) 1960, 24, 1201.

[21] E. C. Subbarao, Phys. Chem. Solids 1962, 23, 665.

[22] R. D. Shannon, Acta Crystallogr., Sect. A: Cryst. Phys, Diffr., Theor. Gen. Crystallogr. 1976, 32, 751

[23] V. K. Seth, W. A. Schulze, IEEE Trans. Ultrason. Ferroelectr. Freq. Control 1989, 36, 41.

[24] T. Takenaka, K. Sakata, Jpn. J. Appl. Phys. 1980, 19, 31.

\section{Self-Organization of Semiconducting Polysiloxane-Phthalocyanine on a Graphite Surface**}

\author{
By Paolo Samorí,* Hans Engelkamp, \\ Pieter A. J. de Witte, Alan E. Rowan, \\ Roeland J. M. Nolte,* and Jürgen P. Rabe*
}

The fabrication of molecular or supramolecular wires ${ }^{[1]}$ requires the design of rod-like objects with an intrinsic electrical conductivity, a notable stiffness, and a length on the order of tens of nanometers. An ordered assembly of these anisometric nanostructures should be possible in thin films. Post treatments such as thermal annealing have been successfully used to increase the degree of order in submicrometer sized molecular architectures assembled at surfaces ${ }^{[2-4]}$ and, on the tens of nanometers scale, in long monodisperse alkane layers. ${ }^{[5]}$ Scanning force microscopy $(\mathrm{SFM})^{[6]}$ and scanning tunneling microscopy $(\mathrm{STM})^{[7]}$ offer direct access to the structural properties of (macro)molecules over a wide range of length scales spanning from the subnanometer up to the micrometer scale. ${ }^{[8]}$

Here, we report on the effect of thermally induced self-organization at elevated temperatures in dry ultrathin films consisting of rod-like semiconducting polymers, assembled on graphite and characterized on the single molecule scale. Moreover, we compare these results with those obtained by studying the solvent-induced columnar ordering of the same macromolecules at the solid-liquid interface. While the former approach is technologically more interesting, the latter provides useful insight into the potential of the wet-processing to obtain ordered nanostructures at surfaces.

The rod-like object chosen is a functionalized phthalocyaninato-polysiloxane (PSPc) (Fig. 1) ${ }^{[9]}$ Its monomeric phthalo-

[*] Dr. P. Samorí

Instituto per la Sintesi Organica e la Fotoreattività, C.N.R.

via Gobetti 101, I-40129 Bologna (Italy)

E-mail: samori@isof.cnr.it

Dr. P. Samorí, Dr. P. A. J. de Witte

Institut de Science et d'Ingénierie Supramoléculaires

Université Louis Pasteur

8 Rue Gaspard Monge, F-67000 Strasbourg (France)

Prof. R. J. M. Nolte, Dr. H. Engelkamp, Prof. A. E. Rowan,

Dr. P. A. J. de Witte

NSRIM, Department of Organic Chemistry, University of Nijmegen

Toernooiveld, NL-6525 ED Nijmegen (The Netherlands)

E-mail: r.nolte@science.ru.nl

Prof. J. P. Rabe

Department of Physics, Humboldt University Berlin

Newtonstrasse 15, D-12489 Berlin (Germany)

E-mail: rabe@physik.hu-berlin.de

[***] This work was supported by the EU through the TMR project SISITOMAS (project reference FMRX970099), and the Marie Curie EST project SUPER, by the Deutsche Forschungsgemeinschaft (Sfb448 "Mesoskopisch strukturierte Verbundsysteme") and by the European Science Foundation both through the SMARTON and the EUROCORES-SONS-BIONICS programmes. Supporting Information is available online from Wiley InterScience or from the author. 